\title{
Rüzgar ve Dalga İkliminin Modellenmesi: Gökçeada Örneği*
}

\author{
Asu İnan ${ }^{1 * *}$, Kağan $\mathrm{Cebe}^{2}$, Alper Ankara $^{3}$ \\ 1 Gazi Üniversitesi, Mühendislik Fakültesi, İnşaat Mühendisliği Bölümü, Ankara, Türkiye (ORCID: 0000-0003-2569-2456) \\ 2 Nevşehir Hacı Bektaş Veli Üniversitesi, Mühendislik Fakültesi, İnşaat Mühendisliği Bölümü, Nevşehir, Türkiye (ORCID: 0000-0000-1288-1362) \\ ${ }^{3}$ Gazi Üniversitesi, Mühendislik Fakültesi, İnşaat Mühendisliği Bölümü, Ankara, Türkiye
}

(Konferans Tarihi: 5-7 Mart 2020)

(DOI: 10.31590/ejosat.araconf19)

\begin{abstract}
ATIF/REFERENCE: İnan, A., Cebe, K. \& Ankara, A. (2020). Rüzgar ve Dalga İkliminin Modellenmesi: Gökçeada Örneği. Avrupa Bilim ve Teknoloji Dergisi, (Özel Sayı), 144-151.

$\ddot{O} z$

Rüzgar ve dalga iklimlerinin modellenmesi, kıyı mühendisliği problemlerinin çözümünün ilk adımıdır. Kıyı bölgesinin hidrodinamiğinin anlaşılmasında, kıyı yönetiminin planlanmasında öncelikle rüzgar ve dalga iklimlerin belirlenmesi gereklidir. Rüzgâr ve dalga kaynakları uzun dönem verilere dayalı ve güvenilir olmaz ise yapılacak tasarımlar da güvenilir olamaz. Kullanılan rüzgar verilerinin güvenirliliği, ekonomik ve teknik yönden optimum tasarım yapabilmek için önemli bir önceliktir. Coğrafi bilgi sistemi (CIS) ve bulut hesaplama tabanlı HYDROTAM-3D, üç boyutlu hidrodinamik, türbülans ve taşınım modelidir. HYDROTAM3D modeli hidrodinamik, dalga ilerlemesi, taşınım, su kalitesi, türbülans, rüzgar ve dalga iklimleri, kıyısal sediman alt modelleri olan, kıyı mühendisliğinin birçok problemine cevap veren bir modeldir. Bu çalışmada Gökçeada'ya uygulanmıştır. Ege Denizi'nde yer alan Gökçeada, Türkiye'nin en büyük adasıdır. Rüzgar verileri olarak Gökçeada Meteoroloji İstasyonu ve ECMWF (Avrupa Orta Vadeli Tahminler Merkezi) verileri, rüzgar ikliminin HYDROTAM-3D ile modellenmesinde kullanılmıştır. İki farklı veri setinden elde edilen rüzgâr iklimi tahminleri karşılaştırılmıştır. Uzun dönem rüzgar istatistiklerine dayanılarak Gökçeada denizel alanı için rüzgar gülü; aylara, yıllara ve yönlere göre maksimum rüzgar hızları sunulmuştur. Dalga iklimi için, ECMWF verileri kullanılmışıı. Dalga tahminlerinde WAM modeli ve CEM modeli uygulanmış ve tahminler karşılaştırılmıştır. Uygulanan WAM modeli sayısal bir model iken, CEM modeli amprik bir modeldir ve her ikisi de uzun dönem istatistiğine dayanmaktadır. Her iki dalga modelinim tahminlerine göre belirgin dalga yüksekliği ile dalga periyodu grafiği, aylık ortalama ve en uç değer belirgin dalga yükseklikleri, yıllık ve mevsimlik dalga gülü sunulmuştur. Gökçeada denizel alanı için elde edilen rüzgâr ve dalga iklimi tahminleri bölgedeki kıyı yapılarının tasarımında, kıyı mühendisliği problemlerinin çözümünde, kıyı bölgesinin rüzgâr ve dalga enerjisi potansiyellerinin belirlenmesinde, kamu kurumlarının kıyı alanları yönetimi planlamalarında kullanılabilecektir.
\end{abstract}

\section{Modeling of Wind and Wave Climate: Gökçeada Case}

\begin{abstract}
Numerical modeling of wind and wave climate is the first step for the solutions of the coastal engineering problems. Determination of wind and wave climate has a primary role to understand the hydrodynamics of the coastal zone and plan of the coastal zone management. If the data sets are not based on the long terms and reliable, the designs cannot be reliable. The reliability of the wind data has the important priority to be able to have the optimum solution of the designs economically and technically. The HYDROTAM-3D, which is geographic information system (GIS) and cloud computing based, three dimensional hydrodynamic, turbulence and transport model, has been applied to Gökçeada coastal waters. HYDROTAM-3D is a model, that solves so many problems of coastal engineering. It has hydrodynamic, wave propagation, transport, water quality, turbulence, wind and wave climate, coastal sediment submodules. Gökçeada is the biggest island of Turkey, which is located in the Aegean Sea. Wind data of the meteorological station in Gökçeada and ECMWF (European Center for Medium-Range Weather Forecasts) wind data are used for the wind climate modeling in the HYDROTAM-3D. The predictions of the wind climate based on two different wind data are compared. Wind rose, maximum wind speeds depending on months, years and directions based on the long-term wind statistics for the Gökçeada coastal region are presented. For the prediction of the wave climate, ECMWF wind data has been used. WAM model and CEM model are applied and compared for the wave predictions. WAM model and CEM model are used a numerical method and an empirical method, which are based on long term statistics, respectively. The graph of significant wave height vs. wave period, monthly average
\end{abstract}

\footnotetext{
* Bu makale International Conference on Access to Recent Advances in Engineering and Digitalization (ARACONF 2020) de sunulmuştur.

** Sorumlu Yazar: Gazi Üniversitesi, Mühendislik Fakültesi, İnşaat Bölümü, Ankara, Türkiye, ORCID: 0000-0003-2569-2456, asuinan@,gazi.edu.tr
} 
and extreme significant wave heights, yearly and monthly wave roses are presented based on the predictions of the two wave models. The predictions of wind and wave climates for the Gökçeada coastal region can be used for the design of the coastal structures, solving of coastal engineering problems, determination of the potential of wind and wave energy, planning of coastal zone management of the state agencies for this region.

Keywords: Wind climate, Wave climate, HYDROTAM-3D, WAM model, CEM model, Modeling

\section{Giriş}

Bir kıyı alanındaki rüzgâr ve dalga ikliminin belirlenmesi o bölgenin hidrodinamiğinin anlaşılması, kıyı mühendisliği tasarımları, kıyı alanları yönetimi ve planlaması için yapılması gereken çalışmaların temelini oluşturmaktadır.

Rüzgâr ve dalga iklimlerinin güvenilir bir şekilde belirlenebilmesi için, kullanılacak veri serilerinin uzun dönemli ve güvenilir olması gereklidir. Aksi takdirde rüzgâr ve dalga iklimini temel alan çalışmalar ve tasarımlar da etkin çözümlerden uzak olacaktır.

Türkiye kıyılarında genellikle dalgalar, rüzgâr kökenli dalgalardır.

Rüzgâr tahmin verileri için iki ölçüm yöntemi bulunmaktadır: Deniz ve karaya rüzgâr ölçüm aletleri kullanılarak yapılan ölçümler ve rüzgâr basınç farklarından yararlanılarak yapılan ölçümler. Deniz ölçümlerinden daha güvenilir veriler elde edilirken, kara ölçümleri deniz ölçüm verilerinin olmadığı yerlerde belirli katsayılarla çarpılarak, kalibre edilip kullanılabilir. Rüzgâr basınç farklarından yararlanmak daha karmaşık olduğundan kara ve deniz ölçümlerin olmadığı bir ortamda seçenek olarak düşünülebilir (Buyruk, 2019).

Rüzgâr verileri analiz edilip rüzgâr iklimleri oluşturulduktan sonra, rüzgâr kökenli dalgaların modellenmesi süreci başlar. Bu konuda birçok araştırma yapılmış, modellemeler için amprik ve sayısal yöntemler önerilmiştir.

En çok kullanılan ampirik modeller, SMP, JONSWAP, SPM ve CEM yöntemleridir.

Dalga tahmini çalışmaları 1940’lı yıllarda ampirik modellerle başlamıştır. İlk dalga sınıflandırması Sverdrup ve Munk tarafından 1947'de yapılmış, ardından Bret Schneider tarafından 1952'de bu verilerin üzerine eklemeler yapılarak model geliştirilmiştir. Ampirik yaklaşımların temelini, etkin dalga kabarma mesafesi ile dalga büyümesi arasındaki yasa oluşturmaktadır. Bu yasa sonucunda sabit bir etkin dalga kabarması mesafesinde sabit bir yönde ve hızda esen rüzgârın oluşturduğu dalgaların büyümesi, etkin dalga kabarma mesafesinin boyutu ile sinırlıdır (Al-Sammarraie, 2019).

1950’li yıllarda spektral yöntemlere geçilmiş ve daha iyi sonuçlar verdiği gözlemlenmiştir. Spektral yöntemler dalgaların frekanslarına dayanmakta ve dalganın kinetik ve potansiyel enerjilerini gözönüne almaktadır. Philips, 1958'de dalganın lineer olarak büyüdüğünü söylemiştir. Pierson ve Moskowitz, 1964'te Philips'in parametrelerini tanımlamış ve Pierson-Moskowitz spektrumunu geliştirmişlerdir. Böylece birinci kuşak dalga modelleri oluşturulmuştur. 1964'ten sonra Hasselmann ve diğerleri, dalga etkileşimini inceleyerek ikinci kuşak dalga modellerini geliştirmişlerdir (Al-Sammarraie, 2019). 1980'de Hasselmann ve diğerleri, üçüncü kuşak dalga modellerini ortaya atmışlardır. İkinci kuşak ve üçüncü kuşak dalga modelleri arasında fark, çözüm yönteminin farklılığıdır. Üçüncü kuşak dalga modelleri, doğrusal olmayan dalga-dalga etkileşimini spektral şeklin kısıtlamalarının çoğunu azaltarak, daha detaylı bir parametrelendirme ile dalga büyümesini modellemektedirler. WAM modeli üçüncü kuşak dalga modeline örnek olarak gösterilebilir (Buyruk, 2019).

\section{Materyal ve Metot}

Gökçeada, Türkiye'nin en büyük adası olup Ege Denizi'nde yer almaktadır (Şekil 1). İklim olarak, Ege ve Marmara Bölgelerinin iklimlerinin kesiştiği bir yerdedir. Oldukça sarp ve engebeli bir arazi yapısına sahip olan ada yüksek tepeler, derin vadilerden oluşur. Gökçeada, Çanakkale iline bağlı olup, 2019 yılı itibariyle yaklaşı 10000 nüfusa sahiptir. Adada üç adet liman bulunmaktadır: Kuzu Limanı, Kaleköy Limanı, Uğurlu Limanı (Gökçeada Tanıtım, 2019).

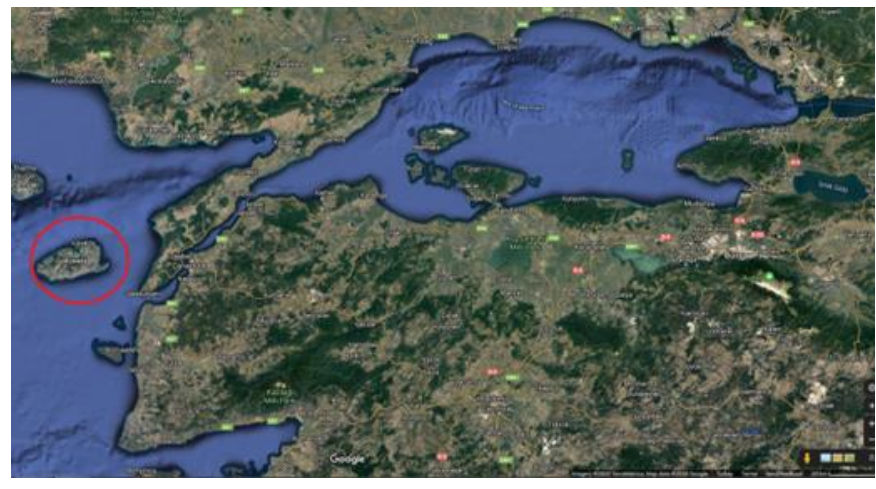

Şekil 1. Gökçeada'nın Konumu (Googlemaps, 2019)

Çalışmada HYDROTAM-3D modeli, rüzgâr ve dalga iklimlerinin belirlenmesi için kullanılacaktır. HYDROTAM-3D, literatürdeki kaynaklarda bulunan analitik ve deneysel sonuçlarla ve saha ölçümleri ile karşılaştırılarak gerçeklenmiştir. Model, üç 
boyutlu hidrodinamik ve taşınım modelidir. HYDROTAM-3D, coğrafi bilgi sistemi tabanlıdır ve bulut bilişim mimarisini kullanmaktadır (HYDROTAM-3D, 2019; Yılmaz, 2018; Fidanoğlu Yıldırım vd., 2017; Cebe ve Balas, 2016). HYDROTAM-3D'nin alt modelleri Şekil 2'de gösterilmiştir.

Bu çalışmada rüzgâr iklimi ve dalga iklimi alt modelleri kullanılmıştır. Rüzgâr alt modelinde, 1970-2016 içerisinde kaydedilmiş meteorolojik verileri saatlik olarak rüzgâr hızı ve yönü grafiksel olarak içinde bulunmaktadır. Diğer veri seti ise ECMWF'in 20002016 yılları arasında bulunan 0.10x0.10 derecelik aralıklarla konumlandırılmış Türkiye kıyılarını kapsayan 6'şar saatlik ölçüm verilerinden oluşmaktadır (Buyruk, 2019; HYDROTAM-3D, 2019).

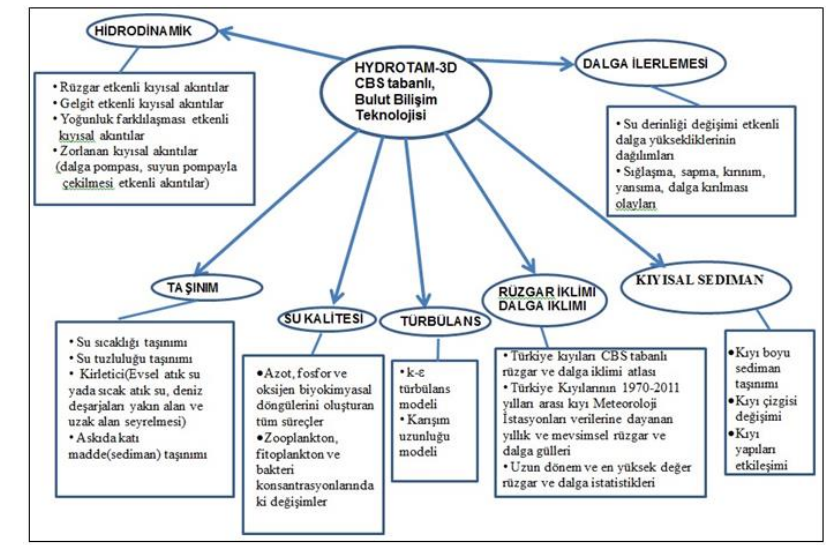

Şekil 2. HYDROTAM-3D alt modelleri (HYDROTAM-3D, 2019)

Türkiye kıyılarında uzun dönem dalga verisi olmadığından ve Türkiye kıyılarındaki dalgaların genellikle rüzgâr kökenli olması dolayısı ile rüzgâr verilerinden dalga iklimine ulaşılmıştır. Bu çalışmada amprik bir yöntem olan CEM metodu ile sayısal yöntem olan WAM modeli dalga iklimi analizleri için kullanılmıştır.

Rüzgar verilerinden dalga tahmini yapılması amacıyla kullanılan CEM metodunda, etkin dalga kabarma mesafesi ile büyüyen dalga oluşumu ampirik olarak benzeștirilmektedir. WAM modelinde ise belirgin dalga yüksekliği, ortalama dalga yönü, frekansı, yönsel spektrumdan elde edilmektedir (Buyruk, 2019).

Çalışma alanımız olan Gökçeada için Gökçeada Meteoroloji İstasyonu ve ECMWF rüzgâr verileri ile rüzgâr iklimleri belirlenmiştir. Dalga iklimi için ise ECMWF verileri ile devam edilmiş; CEM metodu ve WAM modeli uygulanmıştır.

\section{Araştırma Sonuçları ve Tartışma}

\subsection{Rüzgâr İklimi}

Gökçeada Meteoroloji İstasyonu merkezinde kara istasyonu olup, saatlik rüzgâr verileri ECMWF (40.3N, 26E) (Şekil 2) koordinatının 6 saatlik deniz üstü rüzgâr tahminleri ile karşılaştırılmıştır. İki veri setinin karşılaştırması Şekil 3'te verilmiştir.

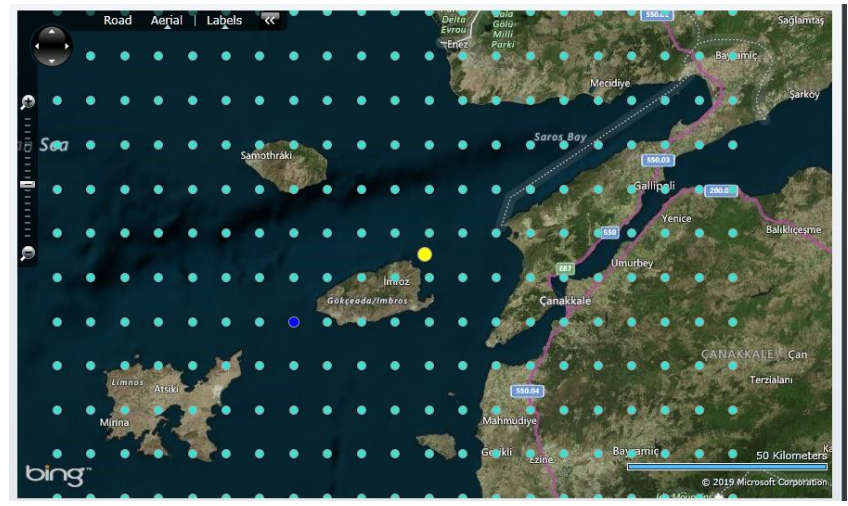

Şekil 3. Gökçeada ECMWF Rüzgâr Verilerinin Kullanılacă̆ı Nokta 40.3N 26E (HYDROTAM-3D, 2019)

Şekil 4'te Gökçeada için 1972-2016 yılları arasındaki meteoroloji istasyonunun altı saatlik karasal rüzgâr ölçümleri ile 2000-2016 yılları için ECMWF (40.3N, 26E) koordinatının rüzgâr tahminleri karşılaştırılmıştır. Şekil 4'te ECMWF (40.3N, 26E) koordinatı verilerinin, Gökçeada meteoroloji istasyonu rüzgâr verilerinin yaklaşık 1.34 katı olduğu görülmektedir. Literatürde deniz aşırı rüzgar, karasal rüzgar verilerinin 1.5-2.0 katı kadardır (Al-Sammarraie, 2019). Gökçeada kıyı alanı için bu değer 1.34'tür. 


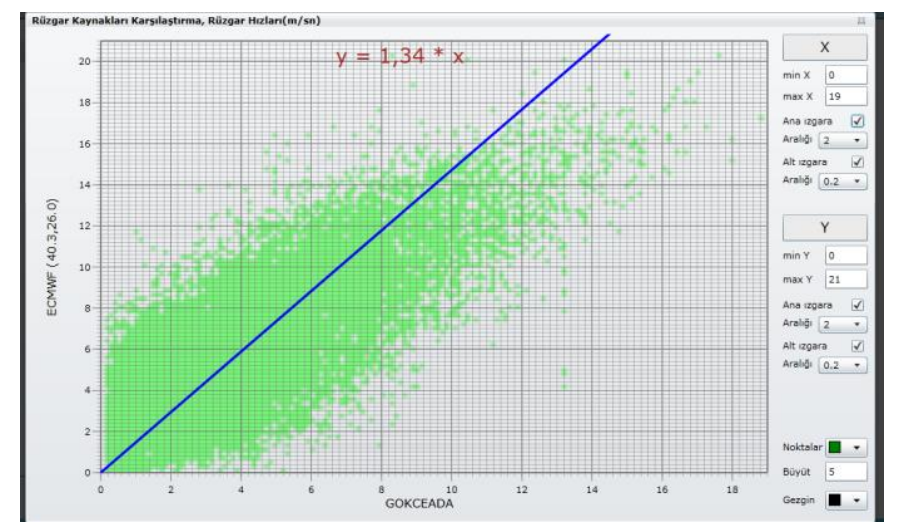

Şekil 4. ECMWF ve Gökçeada Meteoroloji İstasyonları Rüzgâr Verilerinin İlişkisi (HYDROTAM-3D, 2019)

Şekil 5a'da ECMWF rüzgâr tahminleri (40.3N, 26E) hâkim rüzgâr yönünü NE olarak göstermektedir. Şekil 5b'de ise Gökçeada meteoroloji istasyonunun rüzgâr ölçümleri, hâkim rüzgâr yönünün saat yönünde NNE olduğunu göstermektedir.

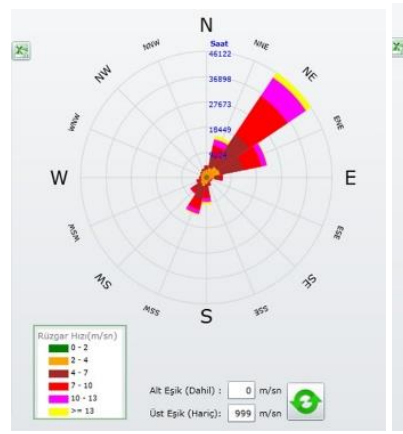

(a)

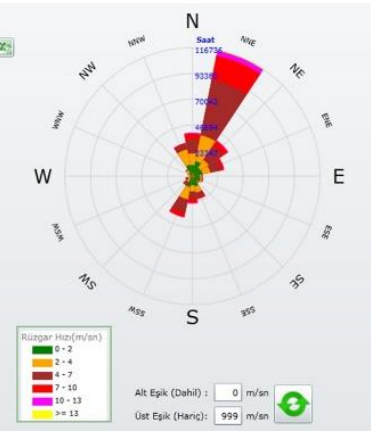

(b)

Şekil 5. a) ECMWF (40.3N,26E) b) Gökçeada Meteoroloji Istasyon verileri b) (HYDROTAM-3D, 2019)

Yıllara göre maksimum rüzgâr hızları Şekil 6'da, ayalara göre maksimum rüzgâr hızları Şekil 7'de verilmektedir.

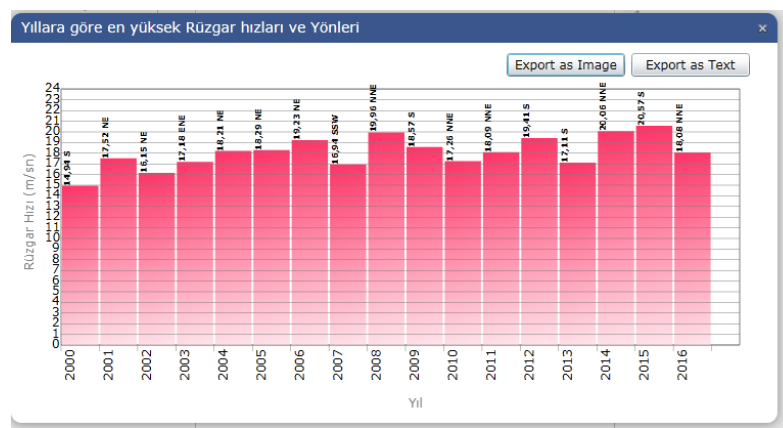

Şekil 6. Ylllara ve Yönlere göre Maksimum Rüzgâr Hızları İstatistiği (HYDROTAM-3D, 2019)

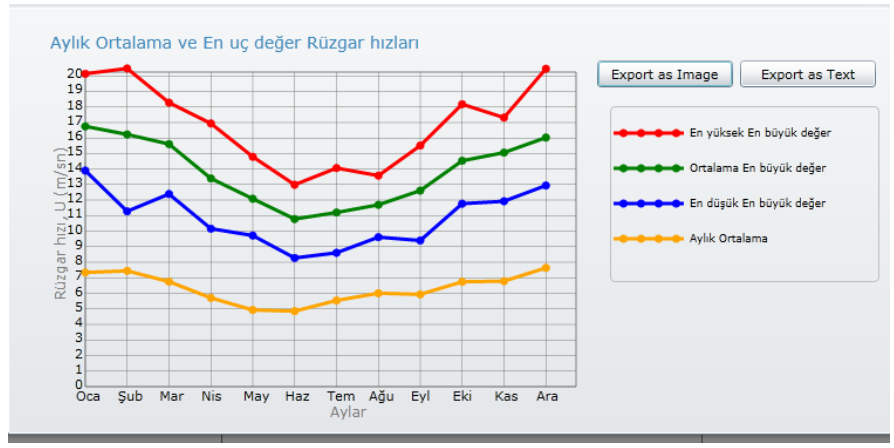

Şekil 7. Maksimum rüzgâr hızları aylara göre (HYDROTAM-3D, 2019) 


\subsection{Dalga İklimi}

Gökçeada dalga iklimi çalışmalarında amprik ve sayısal olmak üzere iki yaklaşım kullanılmıştır. Dalga iklimi analizinde ECMWF'nin rüzgâr verileri kullanılmıştır. İlk yaklaşım amprik bir yöntem olan CEM metodudur, diğeri sayısal bir yöntem olan WAM modelidir. İlk yaklaşımda ECMWF'nin rüzgâr tahminleri, CEM yöntemine girdi olarak ve WAM modelinde ECMWF'nin sayısal dalga tahminleri dalga istatistikleri için kullanılmaktadır. Şekil 8'de Gökçeada için feç mesafeleri gösterilmektedir. En uzun fetch mesafeleri, W yönü ve ardından $\mathrm{N}$ ve ENE'dir.

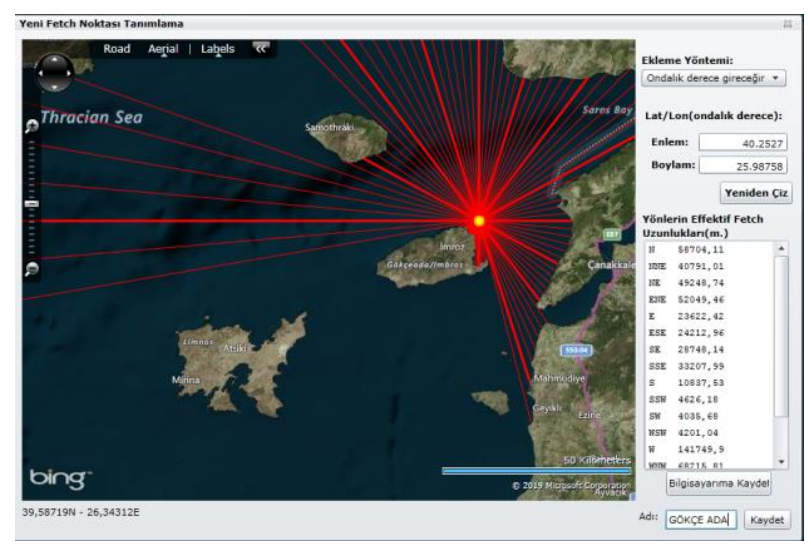

Şekil 8. Gökçeada feç mesafeleri (HYDROTAM-3D, 2019)

\subsubsection{CEM Metodunun Uygulamast}

Bu bölümde, CEM ampirik yöntemi ile uygulanan ECMWF (40.3N, 26E) koordinatından elde edilen rüzgar verileri ile uzun vadeli dalga istatistiklerinin sonuçları verilmiş̧ir.

Belirgin dalga yükseklikleri ile dalga periyodu arasındaki ilişkiyi veren saçılma grafiği Şekil 9 ve dağılım grafiği Şekil 10'da gösterilmektedir. CEM metodu ECMWF (40.3 N 26 E) için dalga modeli $\mathrm{H}_{\mathrm{s}}-\mathrm{T}$ saçılma grafiği Hs-Ts bağıntı grafiği Şekil 10'da verilmiştir.

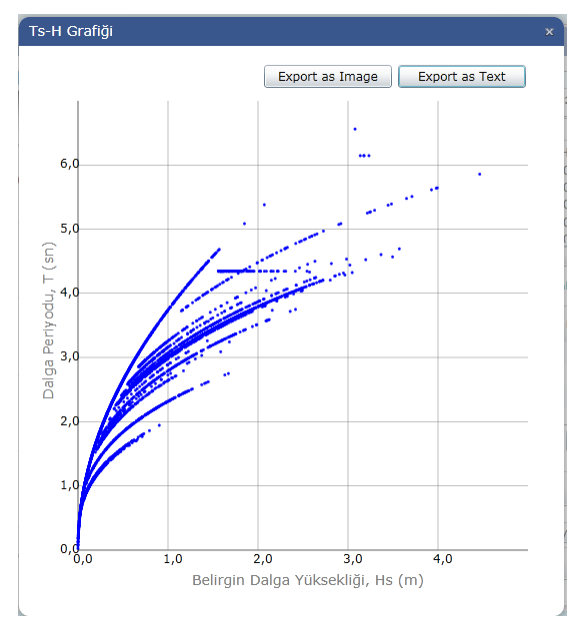

Şekil 9. $H_{s}-$ T Saçılma Grafiği (CEM metodu) (HYDROTAM-3D, 2019)

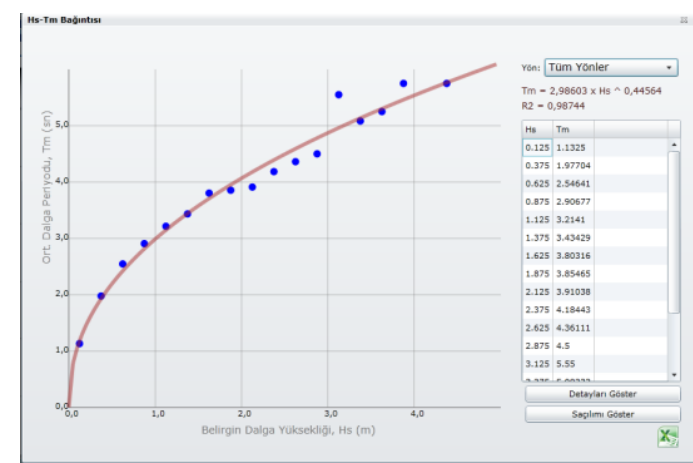

Şekil 10. $H_{s}-T_{m}$ Bağıntısı Grafiği (CEM metodu) (HYDROTAM-3D, 2019) 
Şekil 11'de CEM modeline göre aylık ortalama ve en uç değer belirgin dalga yükseklikleri gösterilmektedir.

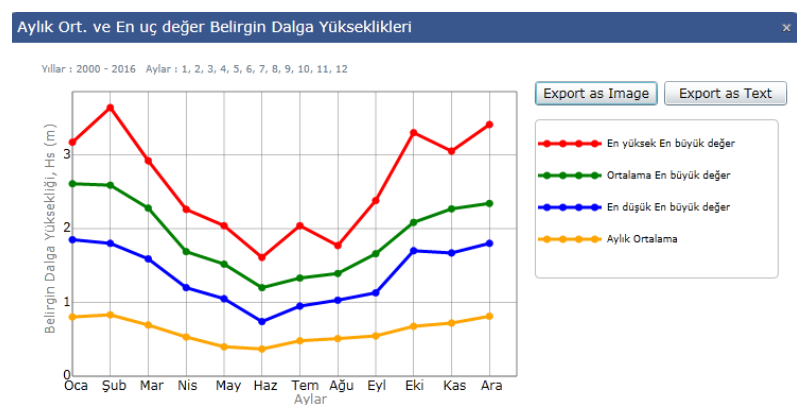

Şekil 11. CEM metoduna göre aylık ortalama ve en uç değer belirgin dalga yükseklikleri (HYDROTAM-3D, 2019)

Yıllık dalga gülleri, belirgin dalga yüksekliğinin tüm yıl boyunca değiş̧ik yönlerden oluşma oranlarını göstermektedir. Dalgaların nereden geldiğini gösteren yön dilimleri, coğrafi yönlerle aynı seçilmiştir. Dalga yüksekliği 0.5 metreden küçükse, denizin durumu "sakin" olarak kabul edilmektedir. Bu durumda herhangi bir dalga yönü belirtilmemekte ve oluşma oranı dalga gülünün ortasındaki çember içinde verilmektedir. Şekil 12'de CEM metoduna dayalı yıllık ve mevsimsel dalga gülleri gösterilmektedir.

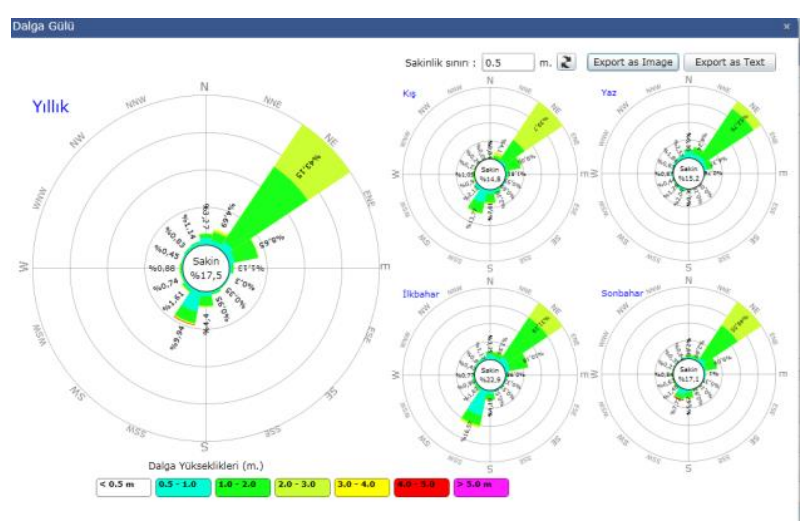

Şekil 12. Ylllık ve mevsimlik dalga gülü (CEM metodu) (HYDROTAM-3D,2019)

\subsubsection{WAM Modelinin Uygulamast}

Belirgin dalga yükseklikleri ile dalga periyodu arasındaki ilişkiyi veren saçılma grafiği Şekil 13 ve dağılım grafiği Şekil 14 'te gösterilmektedir. WAM Modeli ECMWF (40.3 N 26 E) için dalga modeli $\mathrm{H}_{\mathrm{s}}$-T saçılma grafiği Hs-Ts bağıntı grafiği Şekil 10'da verilmiştir. Şekil 15 'de WAM modeline göre aylık ortalama ve en uç değer belirgin dalga yükseklikleri gösterilmektedir. Şekil 16'da WAM modeline göre yıllık ve mevsimsel dalga gülleri gösterilmektedir.

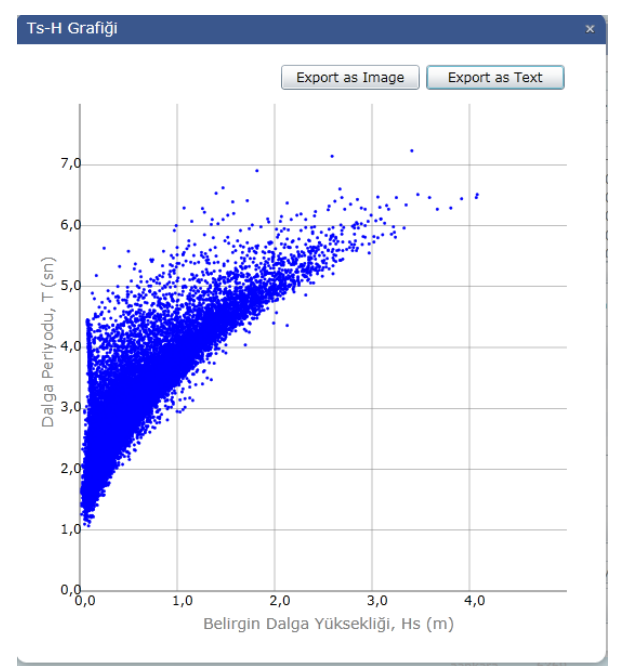

Şekil 13. $H_{s}-$ T Saçılma Grafiği (WAM modeli) (HYDROTAM-3D, 2019) 


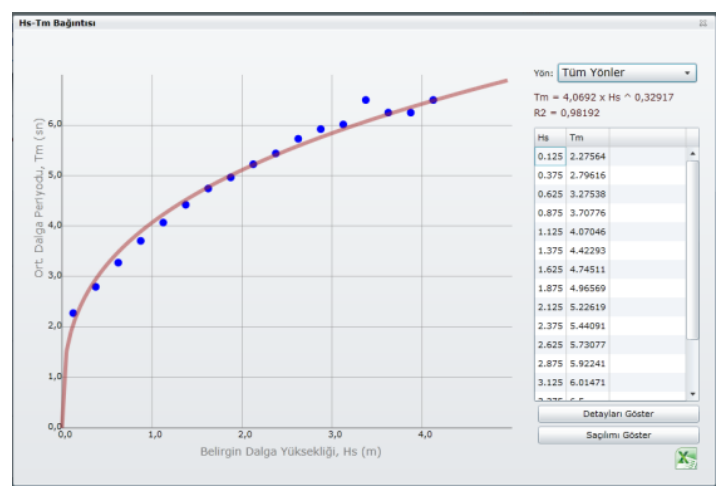

Şekil 14. Hs-Tm bağıntı grafĭgi (WAM modeli) (HYDROTAM-3D, 2019)

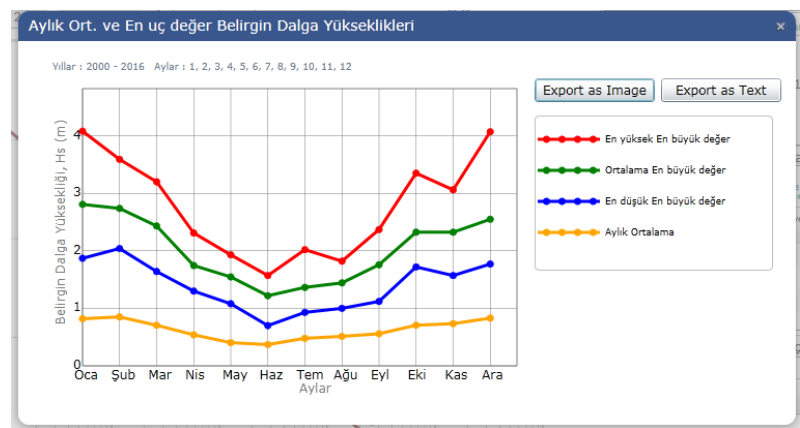

Şekil 15. WAM modeline göre ayllk ortalama ve en uç değer belirgin dalga yükseklikleri (HYDROTAM-3D, 2019)

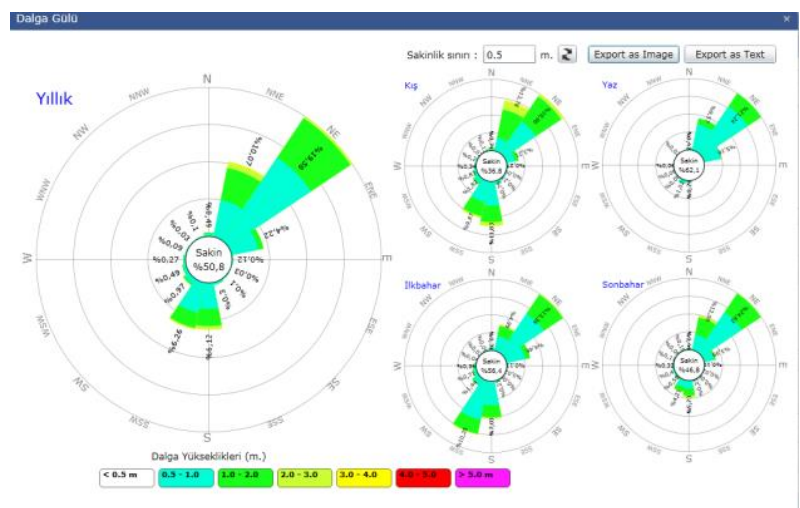

Şekil 16. Gökçeada için yıllık ve mevsimlik dalga gülü (WAM modeli) (40.3N-26E) (HYDROTAM-3D, 2019)

Gökçeada'da en sık rüzgar esen yön, meteoroloji verilerine göre NE, ECMWF verilerine göre NNE olarak gözlemlenmiştir. Meteoroloji istasyonu ölçümleri karasal ölçümlerdir, ancak ECMWF verileri denizel rüzgâr verileridir. Bu nedenle dalga iklimi çalışması yapılırken güvenilirlik açısından ECMWF verileri kullanılmıştır. Gökçeada dalga iklimi verilerinde iki model uygulanmış. Bunlardan birisi CEM ampirik metodu, diğeri ise sayısal metot olan WAM modelidir. Dalga gülüne bakıldığında WAM modelinde \%50.8, CEM metodunda ise \%16.2 sakin deniz koşulları oluştuğu görülmektedir. Bölgedeki belirgin dalga yüksekliği Haziran ayında minimum değerdeyken, Ocak-Şubat aylarında maksimum değeri yakalamaktadır. CEM ampirik metodu ve WAM modeli uzun dönem istatistik verilerine uygulandığında baskın dalga yönü NE olarak görülmektedir. Her iki yöntemin tahminleri uyum içindedir.

\section{Sonuç}

Kıyı mühendisliği uygulamalarının çoğu için rüzgâr ve dalga özelliklerinin incelenmesi gereklidir. Uygulamaların çoğu için uzun vadeli rüzgâr ve dalga verileri gerekir. Türkiye Kıyılarında dalga iklimi çalışmalarında kullanılabilecek uzun dönem ölçülmüş dalga verisi bulunmamaktadır. Bugün dünyada olduğu gibi, Türkiye'de de dalga tahminleri, rüzgâr ölçümlerine ya da modellere dayanmaktadır. Bu çalışmada Gökçeada denizel alanının HYDROTAM-3D alt bölümleri kullanılarak rüzgâr ve dalga iklimi çıkarılmışıır. Gökçeada denizel alanı için elde edilen rüzgâr ve dalga iklimi tahminleri bölgedeki kıyı yapılarının tasarımında, kıyı mühendisliği problemlerinin çözümünde, kıyı bölgesinin rüzgâr ve dalga enerjisi potansiyellerinin belirlenmesinde, kamu kurumlarının kıyı alanları yönetimi planlamalarında kullanılabilecektir.

\section{Teşekkürr}

HYDROTAM-3D modeli için DLTM Yazılım Teknolojileri San. ve Tic. Ltd. Şti.'ne teşekkür ederiz. 


\section{Kaynakça}

Buyruk, T., (2019), Türkiye Klyllarındaki Rüzgâr ve Dalga İklimi ile Enerji Potansiyelinin CBS Tabanlı Elektronik Atlası, Doktora Tezi, Gazi Üniversitesi Fen Bilimleri Enstitüsü, Ankara, Türkiye.

Al-Sammarraie K., .(2019), A Comparative Study on the Wave Climate of Southern Aegean Coastline of Turkey., MSc Thesis, Atılim University, Institute of Science and Technology, Ankara, Turkey, 2019.

Gökçeada Tanıtım web sitesi, (2019), www.gokceada17.com/taltkat/gokceada-hakkinda-genel-bilgi_1.

Googlemaps, https://www.google.com/maps/place/G\%C3\%B6k\%C3\%A7eada\%2F\%C3\%87anakkale/@ 39.7669856,25.9396144,8.77z/data=!4 m5!3m4!1s0x14b02d44bc69c92b:0xd4fbaaf8fe8a67f7!8m2!3d40.1621148!4d25.8285153

HYDROTAM-3D, (2019), 3-D Hydrodynamic Transport Model website, http://hydrotam.com.2019

Y1lmaz, N., (2018), Modeling of wind climate, wave climate and current pattern in Samsun Bay coastal waters, Journal of the Faculty of Engineering and Architecture of Gazi University, 33(1), 279-297.

Fidanoğlu Yıldırım, P. İnan, A., Balas, L., Yılmaz, N., Cebe, K., (2017), The need for the integration of land use planning and water quality modelling in the case of Fethiye Bay, Journal of Polytechnic, 20 (2), 427-435.

Cebe, K., Balas, L., (2016), Water quality modelling in Kaş Bay, Applied Mathematical Modelling, 40 (3), $1887-1913$. 